\title{
Conhecimento e adesão à doação de leite humano de parturientes de um hospital público
}

\author{
Knowledge and adhesion to donation of human milk of women who gave birth \\ in a public hospital
}

\section{Connaissances et adhesion a la donation du lait humain des mers dans I'hôpital public}

\section{Conocimiento y adhesión a la donación de leche humana de madres en un hospital publico}

\author{
Karla Toledo Candido Muller ${ }^{1}$ \\ Ana lara Pereira de Souza ${ }^{2}$ \\ Juliana Maria Ferreira Cardoso ${ }^{1}$ \\ Durval Batista Palhares ${ }^{2}$
}

Recebido em: 20/04/2017; revisado e aprovado em 25/07/2017; aceito em 16/08/2017

DOI: http://dx.doi.org/ 10.20435/inter.v0i0.1588

\begin{abstract}
Resumo: Visando identificar o conhecimento e a prática de parturientes sobre a doação de leite humano, foram entrevistadas 30 parturientes, antes e após 15 dias do parto. O banco de leite humano era desconhecido por $53,3 \%$ destas, e o processo de doação, por $27,0 \%$, independente do número de consultas no pré-natal. Apesar de $90,0 \%$ desejarem doar seu leite, apenas 30,0\% o fizeram, sem associação entre desejo e prática. A falta de informação no pré-natal parece limitar essa prática de doação de leite humano.
\end{abstract}

Palavras-chave: aleitamento materno; leite humano; bancos de leite humano; saúde materno-infantil.

Abstract: Aiming to identify the knowledge of parturients about the human milk donation and its adherence after orientations, 30 parturients were interviewed before and after 15 days of delivery. Regardless of the number of prenatal consultations, the human milk bank was unknown by $53.3 \%$ and the donation process by $27 \%, 90 \%$ wanted to donate their milk, but only $30 \%$ donated, with no association between desire and practice. The lack of information in prenatal care seems to limit this practice of giving.

Keywords: breastfeeding; human milk; banks of human milk; maternal and child health.

Résumé: Pour identifier la connaissance des mères sur le don de lait maternel et de ses membres après les directrices ont été interrogées 30 femmes enceintes avant et après 15 jours de livraison. Quel que soit le nombre de consultations dans le période prénatale, la banque de lait humain était inconnue pour 53,3\% et le processus de don pour 27\%, 90\% voulaient faire don de leur lait, mais seulement $30 \%$ on fait don, avec aucune association entre le désir et la pratique. Le manque d’information sur prénatale semble limiter cette pratique de donner.

Mots-clés: I'allaitement maternel; le lait humain; les banques de lait humain; sante maternelle et infantile.

Resumen: Con el objetivo de identificar el conocimiento de las parturientas acerca de la donación de leche humana y su adherencia después de orientaciones, 30 parturientas fueron entrevistadas antes y después de 15 días de entrega. Independientemente del número de consultas prenatales, el banco de leche humana era desconocido por el 53,3\% y el proceso de donación por $27 \%$, el $90 \%$ quería donar su leche, pero sólo el $30 \%$ han donado, con ninguna asociación entre el deseo y la práctica. La falta de información en la atención prenatal parece limitar esta práctica de donar.

Palabras clave: la lactancia materna; la leche humana; bancos de leche humana; salud materno-infantil.

\footnotetext{
${ }^{1}$ Universidade Católica Dom Bosco (UCDB), Campo Grande, Mato Grosso do Sul, Brasil.

${ }^{2}$ Universidade Federal de Mato Grosso do Sul (UFMS), Campo Grande, Mato Grosso do Sul, Brasil.
} 


\section{INTRODUÇÃO}

Devido às suas propriedades imunológicas, hormonais, endócrinas e nutricionais, o leite humano é considerado um alimento natural e seguro para a saúde de todos os recém-nascidos (RN), proporcionando seu desenvolvimento e crescimento saudável. Desse modo, os Bancos de Leite Humano (BLH) fornecem leite humano pasteurizado como uma possibilidade para os lactentes que, perante comprovação clínica, não possuam acesso ao aleitamento materno, como prematuros, RN de baixo peso ou hospitalizadas em Unidades de Tratamento Intensivo Neonatal (GALVÃO; VASCONCELOS; PAIVA, 2006; KENNAERGH; LOCKHART-BORMAN, 2011).

O BLH não visa à lucratividade, sendo ilegal a compra ou venda de leite humano, o qual deve ser doado por nutrizes sadias, que produzam leite em quantidade superior às exigências de seu filho. Também é sua função incentivar o aleitamento materno, fornecer orientação às puérperas e lactentes sobre "pega", posição durante a mamada e realizar o acompanhamento destas quando há dificuldade na prática da amamentação, contribuindo para a redução da mortalidade neonatal através de medidas educativas (BRASIL, 2008).

A infância é considerada o momento ouro para o desenvolvimento de grande parte das potencialidades humanas e qualquer alteração nesse período é passível de provocar graves danos, tanto para o indivíduo como para toda a sociedade. Além de o leite materno ser reconhecido internacionalmente como a maior estratégia natural de vínculo, afeto, proteção e nutrição para a criança, é também a mais econômica e eficaz intervenção para redução da morbimortalidade infantil (BRASIL, 2015).

O desenvolvimento psicossocial da criança é considerado mundialmente como um dos preditores mais importantes para a produtividade de uma região ou país e está diretamente influenciado pelo aleitamento materno exclusivo. Alguns desses fatores justificam a doação para RNs que não podem receber o leite de suas mães. O primeiro se deve à presença de ácidos graxos poli-insaturados de cadeia longa, considerados essenciais para o desenvolvimento cerebral e da retina, principalmente logo no início da vida, e as fórmulas lácteas comercializadas atualmente são isentas desses lipídeos (PÉREZ-ESCAMILLA; MORAN, 2017).

Outro fator está relacionado às propriedades biológicas do leite humano, que podem promover um melhor desenvolvimento motor e intelectual, e o uso de leite de outras espécies podem desenvolver alterações imunológicas e gástricas. Em terceiro lugar, o AME parece ter efeito protetor contra a obesidade infantil, considerada uma epidemia moderna, gerando grandes consequências psicossociais e fisiopatológicas para a criança (BRASIL, 2015; PANCZUK et al., 2016; PÉREZ-ESCAMILLA; MORAN, 2017).

Apesar do reconhecimento dos benefícios da amamentação para as crianças, assim como para as mulheres e sociedade, ainda há uma quantidade limitada de mulheres doadoras (NEVES et al., 2011). De acordo com Santos et al. (2009), o ingurgitamento mamário é a complicação que mais frequentemente leva as mães a procurar os BLH, sendo inexpressível o número de mulheres que procuram o serviço exclusivamente pelo interesse de doar seu leite.

Segundo Caminha et al. (2010), o ato de amamentar e o desenvolvimento satisfatório da prática da doação de leite humano dependem de como gestantes e nutrizes adquirem tal conhecimento, tratando-se de um ato biologicamente pré-determinado e socioculturalmente imposto. Desse modo, destaca-se a necessidade de identificar o conhecimento das mães quanto à importância da doação de leite humano e relevância dos BLH, colaborando para o 
redirecionamento das ações desenvolvidas pelos BLH e reorientação das práticas seguidas pelos profissionais de saúde, a fim de prevenir o desmame precoce e contribuir com o aumento do número de doadoras de leite humano e volume de leite coletado (SANTOS et al., 2009; PASSARIN; SANTOS, 2009).

Este estudo teve como objetivo identificar o conhecimento de parturientes sobre a importância da doação de leite humano e verificar a mudança de atitude sobre a adesão à doação de leite humano após receber orientações.

\section{MÉTODO}

Estudo descritivo quantitativo realizado no Núcleo Hospital Universitário Maria Aparecida Pedrossian (NHU) - Universidade Federal de Mato Grosso do Sul, Campo Grande/MS, nos meses de janeiro a fevereiro de 2014, após aprovação do Comitê de Ética em Pesquisas com Seres Humanos (CEP/UCDB - parecer n. 24847713.3.0000.5162).

De acordo com o fluxo do hospital, por amostragem não probabilística, foram entrevistadas 33 mulheres em trabalho de parto (parturientes), com tempo de gestação entre 37 a 41 semanas (39,00 \pm 1,08 semanas; média \pm desvio padrão), independente da idade e aparentando condições físicas e cognitivas para responder ao questionário, não sendo inclusas aquelas de risco eminente ou trabalho de parto avançado, assim como mulheres com transtorno mental e indígenas. Foram excluídas duas parturientes por não contemplarem todas as fases da pesquisa e uma devido ao filho sofrer intercorrências, não recebendo alta hospitalar junto à mãe, resultando em 30 parturientes.

O estudo iniciou-se após as participantes ou seus responsáveis legais assinarem o Termo de Consentimento Livre e Esclarecido (TCLE) e Termo de Assentimento para menores de 18 anos. A pesquisa foi dividida em dois momentos: O primeiro momento foi em ambiente hospitalar, com aplicação de uma entrevista estruturada em parturientes sobre seu conhecimento a respeito do BLH, sobre como realizar a doação desse leite, a quem este se destina e seus benefícios. Foi questionado ao final se a mesma teria interesse em doar seu leite. A entrevista foi gravada para transcrição das respostas abertas e posterior análise e categorização destas. Após a entrevista, foi distribuído um material do Ministério da Saúde com orientações acerca do aleitamento materno e doação de leite humano, sendo estes de caráter motivacional e de promoção à adesão a tais práticas.

No segundo momento, após 15 dias ao primeiro encontro, cujo período as mães deveriam estar em casa amamentando seus bebês, foi realizada a coleta de informações, via telefonema, com intuito de identificar informações sobre o processo de adesão da nutriz à prática de doação de leite humano.

Os dados nominais e categóricos foram apresentados em distribuição de frequência absoluta e relativa, enquanto as variáveis quantitativas foram analisadas por meio de média desvio padrão da média, representados em gráficos e tabelas. Aplicou-se o teste de Exato de Fisher para analisar possíveis associações entre as variáveis categóricas e o teste de Correlação Linear de Spearman para analisar correlações entre as variáveis, com nível de significância de 5\%, por meio do Software estatístico Bioestat 5.3. 


\section{RESULTADOS E DISCUSSÃO}

O desconhecimento de $53,3 \%(n=16)$ das parturientes entrevistadas sobre a prática da doação de leite e a existência de Bancos de Leite Humano (BLH) sugere falha no modo como a Política Nacional de Incentivo ao Aleitamento Materno vem sendo conduzida em relação à temática da doação de leite humano. Considerando que o BLH é um dos eixos estratégicos para a promoção, proteção e apoio ao aleitamento materno, esse fato gera preocupações (GIUGLIANI, 2010)

Uma vez que 53,3\% ( $n=16)$ das entrevistadas eram multíparas e 46,7\% ( $n=14)$ primíparas, é possível afirmar que a maioria já havia passado pela experiência do aleitamento e, mesmo assim, não contribuíram para aumentar o número de parturientes que conheciam o BLH e a doação de leite materno. Outro fator discordante do baixo percentual de conhecimento está relacionado à média de idade de $25,13 \pm 5,66$ anos (média \pm desvio padrão), refletindo uma população mais madura, com apoio de um parceiro, pois 63,3\% $(n=19)$ declararam união estável como estado civil, e com nível de escolaridade composto de $56,7 \%$ ( $n=17$ ) com ensino médio, 13,3\% ( $n=04)$ com ensino superior e 30,0\% ( $n=9)$ tendo cursado o ensino fundamental.

Portanto, além das informações não terem sido fornecidas adequadamente pelos profissionais de saúde, também parecem não fazer parte do comportamento social dessas mulheres.

De modo geral, 23,3\% ( $n=07)$ adquiriram conhecimento sobre essa unidade através de serviços que realizam a coleta de leite humano, como hospitais maternidades durante o pós-parto de outras gestações, 20,0\% ( $n=06$ ) souberam do tema por familiares e/ou amigos, enquanto que $13,3 \%(n=04)$ das parturientes relataram ter conhecido o banco de leite humano através de divulgação da campanha do Ministério da Saúde e/ou mídia e 6,7\% (n=02) por profissionais da saúde no pré-natal, havendo mais de uma resposta por mulher entrevistada, corroborando com os estudos de Alencar e Seidl (2009).

Galvão; Vasconcelos e Paiva (2006) consideram urgente a necessidade de divulgação sobre doação de leite materno, uma vez que as campanhas de incentivo à doação são temporárias e geralmente vinculadas a períodos de escassez de leite nos bancos. Segundo Coll, Amorim e Hallal (2010), a mídia é uma ferramenta capaz de influenciar o estilo de vida das pessoas de várias formas, tanto positivamente como negativamente. Desse modo, deveria ser utilizada com o intuito de promover a doação, fornecendo conhecimento e motivação às lactantes, a fim de aumentar a adesão social.

Mesquita (2008) aponta ainda que a mídia influencia o pensamento das pessoas, podendo determinar suas decisões; esse mecanismo de educação em saúde é importante no Brasil devido a aspectos culturais que desfavorecem a prática de doação, tornando-se impactante sua influência da sociedade. Neste estudo, o percentual de mulheres que receberam informações dos BLH ou doações por familiares e/ou amigos não foi elevado e pode refletir na baixa adesão da prática de doação. Quando uma informação é transmitida pelo senso comum, fruto de uma convivência social harmoniosa, fica mais fortalecida sua interiorização e poderia promover uma maior adesão à prática de doação de leite materno, gerando, em longo prazo, uma mudança de paradigmas na sociedade como um todo.

No primeiro momento, os principais fatores listados entre as que afirmaram terem recebido orientações acerca da doação, estavam em consonância com a literatura (BRASIL, 2008; ALENCAR; SEIDL, 2010), como ação manipulativa da mama lactente (coleta/ordenha) descrita por 20,\% 
( $\mathrm{n}=06$ ) delas, incluindo referências à massagem nos seios, ao modo de fazer a ordenha e sobre como colher o leite no frasco; $16,7 \%(n=05)$ detalharam sobre como ocorre o transporte do leite doado, citando a participação do Corpo de Bombeiros; os cuidados com o frasco foram descritos por 6,7\% ( $n=02)$, incluindo o processo de esterilização e congelamento.

No entanto verifica-se que o conhecimento sobre a doação ainda se mostra superficial, com pouco aprofundamento ao controle de excesso de leite, prevenção de mastite e auxílio ao recém-nascido impossibilitado de receber leite de sua própria mãe (LUNA; OLIVEIRA; SILVA, 2014). Nenhuma das entrevistadas citou os processos de higienização da nutriz necessários para a ordenha, uso de máscara, touca e tempo máximo de permanência do leite no refrigerador e geladeira.

De acordo com as Normas Técnicas para Banco de Leite Humano publicadas pela Agência Nacional de Vigilância Sanitária (ANVISA), a ordenha é utilizada como um indicador de qualidade para o controle e segurança do leite doado, e o produto final não será utilizado caso apresente alterações organolépticas e microbiológicas (BRASIL, 2008). Para a proteção e conservação das propriedades imunobiológicas e nutricionais do leite utilizado na alimentação de recém-nascidos pré-termo, todos os processos que envolvem a técnica da ordenha devem acompanhar rigoroso controle higiênico-sanitário (SILVA, 2004).

As alegações para uma possível doação após o parto estavam pautadas na solidariedade preferencialmente, enquanto as alegações para não doação se distribuíram de forma equânime. Todas as alegações estão detalhadas na tabela 1.

Tabela 1- Distribuição das alegações das 30 parturientes para a doação ou não doação de leite materno (Campo Grande, 2014)

\begin{tabular}{lccc}
\hline & Alegações & $\mathbf{n}$ & \% \\
\hline Doariam & & \\
Solidariedade & 15 & 50,0 \\
Saúde da Mulher & 9 & 33,3 \\
Excesso de Leite & 4 & 13,3 \\
Família e/ou filho anterior necessitou & 3 & 10,0 \\
Produzir mais Leite & 1 & 3,33 \\
\hline Não Doariam & & \\
Leite Seca & 1 & 3,33 \\
Não se sente preparada & 1 & 3,33 \\
Filho fica mais fraco & 1 & 3,33 \\
\hline
\end{tabular}

Fonte: Elaboração própria.

Apesar de apenas uma entrevistada se preocupar em 'secar seu leite' com a prática da doação, esse argumento reflete a ignorância sobre o assunto. O Ministério da Saúde é enfático ao dizer que "sem o esvaziamento adequado da mama, a produção do leite diminui, por inibição mecânica e química. A remoção contínua dos peptídeos supressores da lactação contidos no leite garante a reposição total do leite removido", portanto, quanto maior a retirada consequentemente o organismo provoca maior produção (BRASIL, 2014, p. 119).

A alegação de que o filho fica mais fraco, pois será retirado o leite, também não possui embasamento científico, pois o leite doado deve ser extraído após a satisfação completa da 
criança e nem todas as mães apresentam produção láctea suficiente para isso, com volume excedente às exigências de seu bebê, devendo haver uma avaliação individualizada, garantindo também que a nutriz seja saudável (BRASIL, 2008).

O que pode diminuir a produção láctea são sintomas com a dor durante as mamadas, geralmente causadas por fissuras decorrentes de uma pega incorreta, sintomas emocionais relacionados ao próprio processo de amamentação como medo e insegurança, que podem desencadear quadros de estresse e/ou ansiedade materna, com consequente inibição na liberação da ocitocina (BRASIL, 2014).

Os fatores culturais não podem ser facilmente modificáveis, necessita de processo de educação em saúde efetivo com visão em curto, médio e longo prazo, com uma mudança de paradigmas para desmistificar crenças e valores que permeiam a doação de leite materno (ALVES et al., 2013) Contudo o sentimento de despreparo relatado por uma das entrevistadas aponta novamente a fragilidade do pré-natal acerca do assunto.

Devido a essas fragilidades, foi instituída em 05 de setembro de 2013, pela Portaria no 1.920, a Estratégia Nacional para Promoção do Aleitamento Materno e Alimentação Complementar Saudável no Sistema Único de Saúde (SUS) - Estratégia Amamenta e Alimenta Brasil (EAAB), resultado da integração de duas ações: a Rede Amamenta Brasil e a Estratégia Nacional para Alimentação Complementar Saudável (ENPACS), a qual possui como objetivos principais,

[...] qualificar as ações de promoção do aleitamento materno e da alimentação complementar saudável para crianças menores de 02 anos de idade [...] e aprimorar as competências e habilidades dos profissionais de saúde para a promoção do aleitamento materno e da alimentação complementar como atividade de rotina das Unidades Básicas de Saúde (UBS). (BRASIL, 2013).

A expectativa sobre essa estratégia é fortalecer as ações dos $B L H$, já que este é um dos principais locais de incentivo ao aleitamento materno, segundo o exemplo do Programa Nacional de Incentivo ao Aleitamento Materno em 1985, proporcionando aos Bancos de Leite Humano ganhar uma proporção significativa na saúde pública brasileira (PONTES et al., 2017).

Todas as parturientes realizaram consulta de pré-natal, com mais de 08 consultas na maioria delas (73,3\%; $n=22)$, contudo não houve correlação entre o número de consultas no pré-natal e o fato de ter recebido alguma orientação acerca da doação de leite humano ( $p=0,95$; $r=-0,01$; Teste de Correlação Linear de Spearman) (Figura 1). Esses dados sugerem que questões relacionadas à doação de leite humano ainda não são tratadas com afinco durante consultas de pré-natal. Embora os programas de pré-natal realizem atividades com ações educativas, comumente estas são focadas no processo de amamentação, como vantagens da amamentação para a saúde da mãe e do bebê, cuidados com as mamas e importância do colostro (ROCCl; FERNADESI, 2014). 
Figura 1- Representação gráfica do número de consultas no pré-natal relacionado à orientação recebida pelas 30 parturientes sobre doação de leite humano.

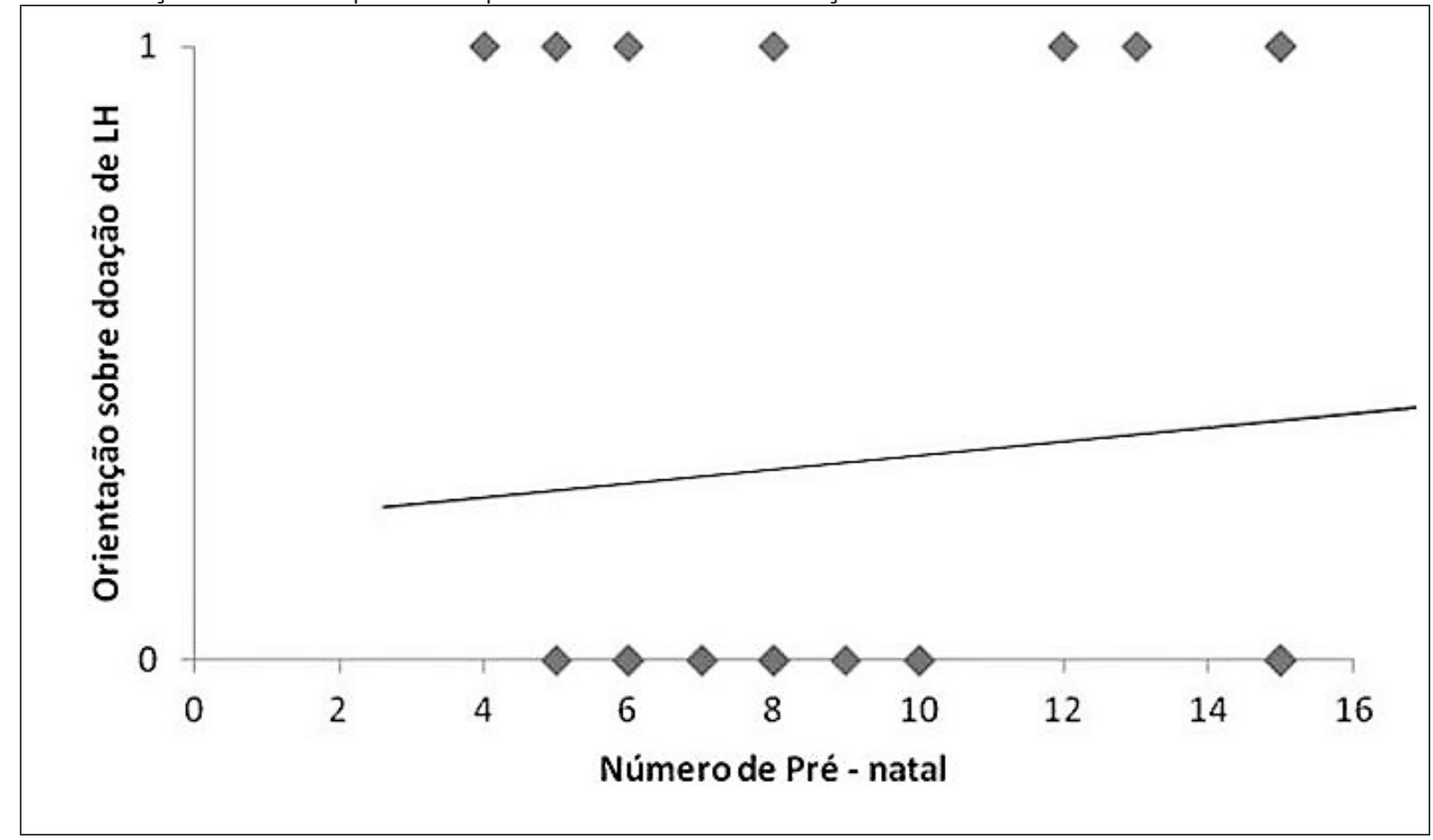

Obs: 0= Não recebeu orientações; $1=$ Sim- recebeu orientações

Fonte: Elaboração própria (2014).

O Ministério da Saúde considera que a orientação no pré-natal é uma das formas capazes de garantir a captação de doadoras (BRASIL, 2008). O comportamento da mulher direcionado para doação não pode ser desenvolvido subitamente, deve ser construído no processo de preparo para a chegada do bebê e as transformações fisiológicas pertinentes ao parto. Entretanto, geralmente, essa informação é repassada somente no pós-parto, e, nesse período, a mulher está apreensiva e com a atenção voltada ao seu filho, tornando tais orientações ineficazes, ou não conseguem compreender a tempo a importância do fato, devido à quantidade de informações recebidas em curso espaço de tempo (GALVÃO; VASCONCELOS; PAIVA, 2006; ALENCAR; SEIDL, 2009; ALVES et al., 2013).

Esses obstáculos também podem estar associados à dificuldade de sensibilizar os profissionais da saúde e gestores quanto à importância da promoção do aleitamento materno e doação de leite (CALDEIRA et al., 2007). Diante dessa problemática, acredita-se que o aumento do recrutamento de doadoras poderá ocorrer a partir do momento em que os profissionais da saúde se dispuserem a incentivar e orientar as gestantes, promovendo entendimento quanto à importância da doação de leite humano (ALVES et al., 2013). Propõe-se que estas comecem a compreender essa ação como uma prática que salva vidas, e não apenas como uma alternativa alimentar.

Silva (2010) destaca que o interesse à doação aumenta quando as doadoras são informadas pelos profissionais da saúde que seu leite se destina a crianças que dele necessita como fator de sobrevivência. Os achados deste estudo comprovam a ideia de que o leite da doadora seja uma alternativa alimentar, pois, durante a primeira entrevista, 50\% ( $n=15)$ das parturientes acreditavam que o leite doado era destinado a crianças que, por algum motivo, estariam impedidas 
de sugar a mama de sua mãe, e 26,7\% ( $n=08$ ) a fatores que impeçam a mãe de amamentar. Fica em destaque, assim como nos estudos de Neves et al. (2011) e de Alves et al. (2013), que o sentimento de solidariedade, os benefícios à saúde da mulher e o excesso de leite são as justificativas mais comuns para a doação.

Contraditoriamente, apesar de 90\% ( $n=27)$ explicitarem a vontade de doar seu leite antes do parto, após 15 dias ao parto foi constatado que apenas 30,0\% ( $n=09$ ) das nutrizes haviam aderido à prática da doação de leite humano, relatando que não tiveram suporte profissional para fazê-lo. Contudo 10,0\% (n=03) das mulheres que negaram o desejo de doação mantiveram esse posicionamento após o nascimento do seu filho, assim como as mesmas alegações para tal recusa. Não houve associação significativa entre o desejo e a prática da doação ( $p=0,53$; Teste de Exato de Fisher) (Figura 2).

Figura 2- Representação gráfica das 30 parturientes de um Hospital Universitário sobre o desejo e a prática de doação de leite humano

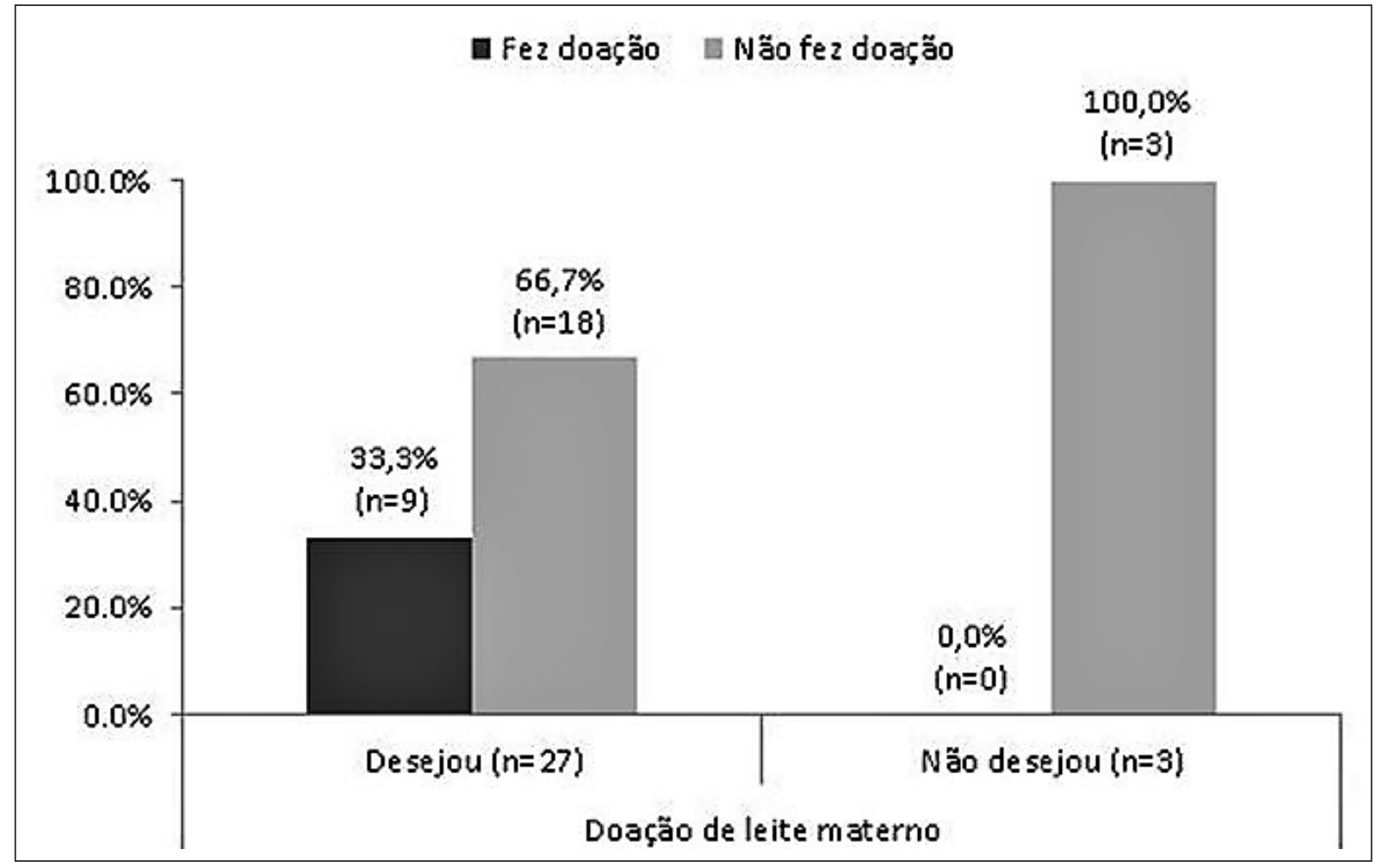

Fonte: Elaboração própria (2014).

No segundo momento, as principais motivações à doação de leite humano estavam mais relacionadas ao bem-estar da própria nutriz, combatendo o desconforto causado pelo excesso de leite e o auxílio do profissional da saúde/corpo de bombeiro no transporte do leite, e o ensino da técnica da ordenha foi descrito como uma conduta facilitadora. Todavia alegações como falta de leite, dificuldade em fazer a ordenha e falta de interesse foram os principais fatores alegados à não adesão à doação de leite humano. Os valores correspondentes às alegações no segundo momento da entrevista estão detalhados na tabela 2. 
Tabela 2- Distribuição das motivações facilitadoras e complicadoras à adesão das 30 nutrizes à doação de leite humano

\begin{tabular}{llc}
\hline \multicolumn{1}{c}{ Motivos } & $\mathbf{n}$ & $\%$ \\
\hline $\begin{array}{l}\text { Facilitadores } \\
\text { Excesso de Leite }\end{array}$ & 7 & 23,3 \\
Auxílio do Profissional da saúde/Corpo de Bombeiro no transporte & 3 & 10,0 \\
do leite e ensino da técnica da ordenha & 2 & 6,7 \\
Ajudar quem precisa (Solidariedade) & 2 & 6,7 \\
Acesso ao Banco de Leite Humano & 2 & 6,7 \\
Não encontrou nenhuma dificuldade durante o processo & 1 & 3,3 \\
Evitar que o leite "empedre" & & \\
Complicadores & 22 & 73,3 \\
Não procurou doar & 15 & 50,0 \\
Pouco Leite & 4 & 13,3 \\
Dificuldade em fazer a ordenha & 2 & 6,7 \\
Falta de Tempo & 2 & 6,7 \\
Não conseguiu entrar em contato com o BLH & 1 & 3,3 \\
Dúvida & & \\
\hline
\end{tabular}

Fonte: Elaboração própria (2014).

A principal motivação da adesão à doação de leite humano identificado pelas entrevistadas foi o excesso de leite, corroborando com estudos científicos (GALVÃO; VASCONCELOS e PAIVA, 2006; SANTOS et al., 2009). Diferentemente, também foi alegado como motivo para a doação de leite humano o auxílio dos profissionais do BLH para ensinar a técnica da ordenha, e a efetividade do corpo de bombeiro no transporte do leite. Importante salientar que a voluntariedade da nutriz é condição absoluta para que o leite ordenhado possa ser utilizado para outras crianças (BRASIL, 2008).

A ordenha é útil para aliviar o desconforto provocado por uma mama muito cheia, para manter a produção de leite quando o bebê não suga ou tem sucção inadequada (ex.: RNs de baixo peso ou doentes), para aumentar a produção de leite e retirar leite para ser oferecido à criança na ausência da mãe ou para ser doado a um banco de leite humano. (BRASIL, 2014, p. 127).

Estudos apontam que a visita dos profissionais do BLH e corpo de bombeiro ao domićlio da doadora esclarece suas dúvidas, além de humanizar o atendimento, possibilitando a troca de saberes entre profissional/nutriz, uma vez que o profissional pode auxiliá-la a desenvolver habilidades que identifiquem suas condições de doadora, como o excesso de leite, sugerindoIhe então fazer a doação. Também orientar sobre a técnica de coleta e provendo os insumos necessários para a doação, garantindo a qualidade das propriedades nutricionais e imunológicas do leite, fortalece a importância da amamentação e previne o desmame precoce (ALENCAR; SEIDL, 2010).

No serviço de saúde em que este estudo foi realizado, os profissionais entram em contato com a nutriz no alojamento da maternidade logo após o segundo dia do nascimento, promovendo o incentivo ao aleitamento materno e fazendo a captação de doadoras, e, após 07 dias, entram em contato novamente com ela por telefone, para verificar se está tendo alguma dificuldade para amamentar e se possui o interesse em doar. 
Torna-se necessária a implantação de modelos que desenvolvam ações de promoção, prevenção e apoio ao aleitamento materno e doação de leite humano, fundamentadas em todos os determinantes da saúde que caracterizam essa população. Investir em estratégias para sensibilizar e capacitar toda a equipe, em tecnologias leves (relacionais) em que o profissional da saúde não detém o saber absoluto, mas usa o conhecimento sociocultural do outro para redirecionar as ações de incentivo ao aleitamento materno.

É indispensável que os BLH mantenham estoque adequado para suprir a demanda das Unidades de Terapia Intensiva Neonatal vinculadas a esse banco, minimizando a mortalidade infantil, em especial a neonatal, porém, de modo em geral, o Brasil apresenta uma estocagem incipiente de leite em seus BLH (GALVÃO; VASCONCELOS; PAIVA, 2006). No Brasil,-deve ser considerado prioridade resolver o problema da falta de conhecimento e de sensibilização dos profissionais de saúde sobre a lactação e sobre os BLH, preferencialmente desde a formação acadêmica, alcançando outros profissionais por meio de ações de educação continuada.

\section{CONCLUSÕES}

Foi identificado que a maioria das entrevistadas desconhecia a prática da doação de leite humano e a existência de bancos de leite humano, embora todas tivessem realizado o pré-natal e algumas parturientes conhecessem ao menos parte do serviço desenvolvido pelos bancos de leite humano. A falta de informação durante o período gestacional parece ser um dos principais motivos ao não desenvolvimento da doação de leite humano.

O desejo de doar seu leite, expressado antes do parto pela maioria das entrevistadas, não se refletiu na mudança de atitude para a prática de doação, sugerindo que, apesar das ações para a promoção da adesão ao aleitamento materno e captação de doadoras de leite humano, fatores socioculturais e psicossociais continuam proporcionando a redução do número de doadoras e, consequentemente, do leite coletado. Desse modo, é evidente a necessidade de pesquisas que investiguem os impactos do treinamento da prática da amamentação e ordenha desenvolvido por uma equipe multiprofissional a partir do pré-natal, no conhecimento e adesão de mulheres à doação de leite humano.

\section{REFERÊNCIAS}

ALENCAR, L. C. E.; SEIDL, E. M. F. Doação de leite humano e apoio social: relatos de mulheres doadoras. Revista Latino-Americana de Enfermagem, São Paulo, v. 18, n. 3, p. 381-9, maio/jun. 2010.

ALENCAR, L. C. E.; SEIDL, E. M. F. Doação de leite humano: experiências de mulheres doadoras. Revista de Saúde Pública, São Paulo, v. 43, n. 1, p. 70-7, fev. 2009. DOI http://dx.doi.org/10.1590/S003489102009000100009.

ALMEIDA, J. A. G.; MAIA, P. R. S.; NOVAK, F. R. Os bancos de leite humano como suporte para a redução da mortalidade infantil: a experiência brasileira. In: CONGRESO URUGUAYO DE LACTANCIA MATERNA, 2., 2004, Montevideo, Uruguay. Anais [...]. Montevideo: Sociedad Uruguaya de Pediatria, 2004. Disponível em: http://www.bvsam.cict.fiocruz.br/evcientif/2culm/2culm.htm. Acesso em: 27 dez. 2013.

ALVES, V. H.; RODRIGUES, D. P.; BRANCO, M. B. L. R.; SOUZA, R. M. P.; SOUZA, R. R. B.; MEDEIROS, F. V. A. Banco de leite humano na perspectiva da mulher doadora. Revista da Rede de Enfermagem do Nordeste, Fortaleza, CE, v. 14, n. 6, p. 1168-76, nov. 2013. 
BRASIL. Ministério da Saúde. Secretaria de Atenção à Saúde. Departamento de Atenção Básica. Saúde da criança: aleitamento materno e alimentação complementar. 2. ed. Brasília: Ministério da Saúde, 2015. 184 p.: il. (Cadernos de Atenção Básica; n. 23).

BRASIL. Ministério da Saúde. Secretaria de Atenção à Saúde. Departamento de Ações Programáticas Estratégicas. Atenção à saúde do recém-nascido: guia para os profissionais de saúde. 2. ed. atual. Brasília: Ministério da Saúde, 2014.

BRASIL. Ministério da Saúde. Portaria n. 1.920, de 5 de setembro de 2013. Institui a Estratégia Nacional para Promoção do Aleitamento Materno e Alimentação Complementar Saudável no Sistema Único de Saúde (SUS)- Estratégia Amamenta e Alimenta Brasil [Internet]. Diário Oficial da União, 6 set. 2013; Seção 1. Disponível em: http://bvsms.saude.gov.br/bvs/saudelegis/gm/2013/prt1920_05_09_2013.html. Acesso em: 16 out. 2014.

BRASIL. Agência Nacional de Vigilância Sanitária. Banco de leite humano: Funcionamento, prevenção e controle de riscos. Brasília: ANVISA, 2008. 160p.

CALDEIRA, A. P.; AGUIAR, G. N. D.; MAGALHÃES, W. A. C.; FAGUNDES, G. C. Conhecimentos e práticas de promoção do aleitamento materno em Equipes de Saúde da Família em Montes Claros, Minas Gerais, Brasil. Cadernos de Saúde Pública, Rio de Janeiro, v. 23, n. 8, p. 1965-70, ago. 2007.

CAMINHA, A. P.; SERVA, V. B.; ARRUDA, I. K. G. D.; BATISTA FILHO, M. Aspectos históricos, científicos, socioeconômicos e institucionais do aleitamento materno. Revista Brasileira de Saúde Materno Infantil, Recife, PE, v. 10, n. 1, p. 25-37, jan./mar. 2010.

COLL, C. V. N.; AMORIM, T. C.; HALLAL, A. P. C. Percepção de adolescentes e adultos referente a influencia da mídia sobre o estilo de vida. Revista Brasileira de Atividade Física e Saúde, Pelotas, RS, v. 15, n. 2, p. 105-10, mar. 2010.

GALVÃO, M. T. G.; VASCONCELOS, S. G.; PAIVA, S. Mulheres doadoras de leite humano. Acta Paulista de Enfermagem, São Paulo, v. 19, n. 2, p. 157-61, abr./jun. 2006.

GIUGLIANI, E. A. A política de promoção, proteção e apoio ao aleitamento materno no Brasil. XI Encontro Nacional de Aleitamento Materno - ENAM. Ministério da Saúde. 2010. Disponível em: http://www.ibfan. org.br/documentos/outras/doc-508.pdf. Acesso em: 16 nov. 2014.

KENNAERGH, J.; LOCKHART-BORMAN, L. The increasing importance of human milk banks. E-Journal of Neonatology Research, v. 1, n. 3, p. 119-25, jan. 2011.

LUNA, F. D. T.; OLIVEIRA, J. D. L.; SILVA, L. R. M. Banco de leite humano e Estratégia Saúde da Família: parceria em favor da vida. Revista Brasileira de Medicina de Família e Comunidade, Rio de Janeiro, v. 9, n. 33, p. 358-64, out./dez. 2014.

MESQUITA, N. C. Mídia e democracia no Brasil: Jornal Nacional, crise política e confiança nas instituições. 2008. Tese (Doutorado em Ciência Política)- Universidade de São Paulo (USP), São Paulo, 2008. Disponível em: http://www.teses.usp.br/teses/disponiveis/8/8131/tde-15092008-101013/pt-br.php. Acesso em: 24 abr. 2014.

NEVES, L. S.; MATTAR, M. J. G.; SÁ, M. V. M.; GALISA, M. S. Doação de leite humano: dificuldades e fatores limitantes. O Mundo da Saúde, São Paulo, v. 35, n. 2, p. 156-61, fev. 2011.

PASSARIN, G. L.; SANTOS, J. S. D. Conhecimento do aleitamento materno em puérperas no Hospital Geral: Caxias do Sul. Pediatria, São Paulo, v. 31, n. 3, p. 152-60, jul./set. 2009. 
PANCZUK, J. K.; UNGER, S.; FRANCIS, J.; BANDO, N.; KISS, A.; O'CONNOR, D. L. Introduction of bovine-based nutrient fortifier and gastrointestinal inflammation in very low birth weight infants as measured by fecal calprotectin. Breastfeeding Medicine: The Official Journal of the Academy of Breastfeeding Medicine, New York, v. 11, n. 1, p. 2-5, jan./fev. 2016.

PÉREZ-ESCAMILLA, P.; MORAN, V. H. The role of nutrition in integrated early child development in the 21st century: contribution from the Maternal and Child Nutrition journal. Maternal and Child Nutrition, United States, v. 13, n. 1, p. 3-6, jan. 2017.

ROCCI, E.; FERNADESI, R. A. Q. Dificuldades no aleitamento materno e influência no desmame precoce. Revista Brasileira de Enfermagem, Brasília, v. 67, n. 1, p. 22-7, jan./fev. 2014.

SANTOS, D. T. D.; VANNUCHI, M. T. O.; OLIVEIRA, M. B.; DALMAS, J. C. Perfil das doadoras de leite do banco de leite humano de um hospital universitário. Acta Scientiarum Health Science, Maringá, PR, v. 31, n. 1, p. 15-21, maio 2009.

SILVA, S. L. Alegações materna para doação de leite humano. 2010. Dissertação (Mestrado em Saúde da Criança e do Adolescente) - Universidade Federal de Pernambuco (UFPE), Recife, 2010. Disponível em: https://repositorio.ufpe.br/handle/123456789/9168. Acesso em: 13 jan. 2014.

SILVA, V. G. Normas técnicas para banco de leite humano: uma proposta para subsidiar a construção para Boas Práticas. 2004. 227p. Tese (Doutorado em Saúde da Mulher e da Criança) - Instituto Fernandes Figueira/Fundação Oswaldo Cruz, Rio de Janeiro, 2004.

\section{Sobre os autores:}

Karla Toledo Candido Muller: Doutorado e mestrado em Saúde e Desenvolvimento da Região Centro Oeste (UFMS (2017). Fisioterapeuta, Mestrado em Fisiologia do Esforço (UNOESTE). Docente na UCDB. E-mail: karla@ucdb.br

Ana lara Pereira de Souza: Fisioterapeuta graduada pela Universidade Católica Dom Bosco (UCDB). Residente do Programa de Residência Multiprofissional em Atenção ao Paciente Crítico (PREMUS/APC) da Universidade Federal do Mato Grosso do Sul (UFMS). E-mail: anaiarapdesouza@hotmail.com

Juliana Maria Ferreira Cardoso: Nutricionista. E-mail juliana_juhmaria@hotmail.com

Durval Batista Palhares: Médico Pediatra. Doutor em Neonatologia. Docente no Programa de Pós-Graduação em Saúde e Desenvolvimento da Região Centro-Oeste da Universidade Federal de Mato Grosso do Sul (UFMS).E-mail: dbpalhares@hotmail.com 